\title{
6 Local policies related to spatial segregation
}

The relevant implementers of local policies related to segregation are similar to those involved in access policies. They include the City Council, the city administration and the political parties which dominate the City Council. Contrary to housing associations the house-owners are primarily interested in increasing their rental income. NGOs and migrant organizations in different European countries are involved in segregation policy to varying degrees. In Eastern European cities such as Vienna, their influence is negligible whereas in British or Dutch cities they play a more important role in the decision-making process.

There are two specific policy challenges for local policies related to segregation.

1. Throughout Europe, ethnic segregation is usually perceived as a policy challenge regarding poorer neighbourhoods, whereas middle and upper middle class ethnic segregation is usually seen to be unproblematic.

2. The extent to which the local authorities can prevent segregation is an issue, and one on which the scientific positions differ widely. The cities' room for manoeuvre is different from one country to the other, and it also varies between cities in the same country.

Segregation policy in European cities tends to follow three general directions:

1. Policies that reduce spatial segregation,

2. Policies that reduce the negative effects of spatial segregation and

3. Policies that manage existing segregation and make positive use of the opportunities which are provided by ethnic segregation.

The policy of reducing spatial segregation is the most promoted and frequently found segregation-related strategy throughout Europe, and it is probably the most realistic political strategy of the three. It may lead to reduction of segregation in the long term, as areas become less disadvantaged and therefore more attractive and less stigmatised for citizens.

Policies of the third type have gained increasing prominence during recent years. Many municipal authorities across Europe have realized that segregation cannot be abolished quickly, and indeed may even have some positive effects. It is unclear whether this strategy will achieve some degree of integration despite existing spatial segregation, and whether this strategy will contribute to some reduction of segregation in the long run.

\subsection{Policies to reduce segregation}

\subsubsection{General principles}

Segregation is a structural feature which cannot be solved at the local level alone. It is necessary to focus on society as a whole. Therefore municipal policy must be complemented by 
- general policy measures that aim to reduce socio-economic polarization within society at large,

- physical planning measures that are carried out with the aim of making neighbourhoods more attractive, bridging rather than dividing different parts of the city,

- measures to improve the quality of existing neighbourhoods though renovation combined with the establishment of shops and services.

- more substantial, stable and long-term political solutions against segregation.

Local municipalities would have to not only choose appropriate anti-segregative measures but also determine what might be an "appropriate" level of social mixing at the neighbourship and the city levels. If a certain level of ethnic concentration is reached in a neighbourhood, a reduction of segregation is nearly impossible or at least very hard to reach. This was empirically proved by Simpson (2005) for a number of British Cities.

Policy measures should try to keep a mix of various ethnic groups in the area. A too high percentage of a dominant ethnic group in a neighbourhood is a barrier against policies to reduce segregation because, once established, ethnic enclaves can only be broken down by forcing measures which would be in contradiction to the democratic values of Western urban societies. The city administration has to be careful over the fact that programmes targeted only for deprived areas carry the risk of increased stigmatisation of these areas. Therefore a preferable choice seems to be an overall programme not only for deprived areas but for as many groups of the local migrant and native population as possible.

In Germany a stringent de-segregation policy is still pursued, despite the fact that political and academic discourse has failed to reach a consensus on its merits. The Federal Building Code requires land use plans to address "the population's housing needs and prevent population imbalances". The Housing Support Law states the obligation to "create and maintain socially stable inhabitant structures" (Münch, 2006). This approach is based on the conviction that immigrants dispersed among the native population will integrate into society more easily. In Germany the association between housing integration policies and the goal to achieve a certain level of ethnic mixing is strong. This goal is explicit and in many housing estates hidden quotas for nonGerman households seem to be the basis for this policy (Harrison et al., 2005: 90).

In France, neighbourhoods with high immigrant concentrations are subjected to "re-equalisation" (NFP France, 2003: 2). Sweden's housing policy is also driven by the aim of breaking down social, ethnic and discriminatory segregation, although this is constructed in socio-economic rather than migrant and minority ethnic terms. The Swedish "big city policy" (officially labelled the Metropolitan Development Initiative, MDI) was focused towards achieving the overall goal of "breaking segregation". This state initiative was launched in 1999 with the twin aims of promoting economic growth and breaking down socioeconomic, ethnic and discriminatory segregation. 


\subsubsection{Residential mobility policy}

A variant of segregation policy is to restrict the inward mobility of all migrants or those belonging to certain ethno-national groups to certain spatial entities via quotas. Such quotas are highly likely to be discriminatory since they can prevent migrant households accessing housing and neighbourhoods to which they would otherwise be entitled. Quotas can be used in two ways:

(1) As a strategic tool designed to disperse migrants (mostly asylum-seekers) across a country, or

(2) In the context of housing allocation, usually within the communal or cooperative sector.

New migrants usually find themselves in the most socially excluded and segregated positions, and may be particular targets of settlement initiatives and quotas. The most obvious group in this category are refugees and asylum seekers. Most EU countries have some planned settlement programme for asylum seekers, which may extend to those granted status as refugees. These programmes usually offer the migrants little choice in where to settle, and are designed to control the entry of new migrants into the country.

Germany has a strict de-segregation policy based on quotas. In particular three groups of immigrants face restrictions to the housing market on the basis of quotas: "Aussiedler", asylum seekers and Jews from the former Soviet Union. In German cities quotas are also in practice in big urban housing estates of communal and cooperative housing.

In Austria there is a mobility policy for asylum seekers. Whereas more than half of the third country nationals live in the ten biggest Austrian cities, asylum seekers do not share this settlement pattern. There are four refugee camps in Austria, where asylum seekers that have made it into the programme of federal care are placed. Not all of them can be accommodated in these camps and might be taken to small boarding houses spread all over Austria and very often located in very sparsely populated areas (NFP Austria, 2003: 48).

MTO, "Moving to Opportunity", is a national model program that has been operated by the U.S. Department of Housing and Urban Development since 1994. It combines tenant-based rental assistance with housing counselling to help very low-income families move from poverty-stricken urban areas to lower-poverty neighbourhoods. It allows the recipient to choose modestly priced private housing in neighbourhoods that can offer ample educational, employment, and social opportunities. The goal is to develop more effective mobility strategies for recipients of tenant-based housing assistance in metropolitan areas throughout the country. Learning from the success of the U.S. MTO Programme consideration should be given to some method of providing families with pre-school and primary school children with priority access to housing which is more suitable to the needs of young children. The difficulty with such a policy would be that it carries the implication that families would be moved out of their priority accommodation as the children become older. 


\subsubsection{Policies to avoid negative effects of gentrification}

Some cities pursue policies to avoid the negative effects of gentrification. Gentrification is a process in which physically deteriorated neighbourhoods experience an increase in rent and property values as a consequence of renovation and by upgrading the housing stock directly or indirectly (e.g., by counselling to the owners). It often forces the low-income residents (both indigenous and migrant) to move out due to the increase of rental payments that usually accompanies this process.

One approach used to tackle segregation is by enhancing the housing quality and social status of marginalized groups through neighbourhood renewal in areas where migrants are settled. A basic assumption in this approach is that urban renewal will relieve tensions between ethnic minorities, which are often exacerbated by social and material deprivation. A typical problem is that renovations of degraded areas have no sustained effect on the situation in the neighbourhood since the implemented measures are only physical renovations or rebuilding activities without a proper consideration of accompanying measures.

In Vienna the Soft Urban Renewal Strategy is one of the world's leading tenant-oriented urban renewal programmes. Urban renewal is understood as an interdisciplinary challenge where social, economic, cultural, aesthetic and ecological demands must be taken into consideration. The City of Vienna decided both against demolition and construction of new urban areas, and against the displacement or compulsory re-housing of those living in such areas. Processes of gentrification were counteracted by the method of "Sockelsanierung" which means that the tenants could stay into their apartments during the whole renovation process. The Viennese model of "soft" urban renewal places residents in the foreground so as to minimise the repression frequently induced by improvement activities. Both owners and residents are involved in the progress. The municipality also grants financial support to tenants with low family income who have problems paying their monthly rent. Currently more than 150,000 apartments (approximately one sixth of the total housing stock) have been renewed with public subsidies. In the context of soft urban renewal, substantial public investments in housing stock and housing quality are combined with the establishment of additional infrastructure and public services.

During the City of Helsinki's 1998 Programme against Social Exclusion and Segregation, the city's administration started to allocate special funds to problematic housing areas. Several offices and departments (the school authority's section for general education, the section for education in Swedish, the social welfare authority and the youth authority) decided to extend the application beyond mere positive discrimination to combating social exclusion and to provision of the entire funds for the local units. The allocation model was based on eight indicators showing local inequality, such as the proportion of people with low education, the general rate of unemployment in the area and the income of families with children. The model defined children of immigrants as its most important target group and the municipal day care centres as 
the appropriate arena. This model allocates funds using a coefficient formed out of the proportion of immigrant children and the proportion of children of Finnish citizens.

\subsection{Policies to reduce negative effects of segregation}

\subsubsection{Urban regeneration programmes}

Urban regeneration programmes which target strategic and sustainable objectives are important initiatives in fighting against the negative outcomes of segregation, and involve the cooperation of professionals and lay people. One important goal is to establish a sustainable social network to support programme which will continue to exist when public funding has run out. Those programmes also provide effective participation possibilities for migrants. REGENERA, for example, was an URBACT network for the exchange of experience on urban regeneration (2004-2006).

In Denmark the Danish Urban Regeneration Programme is one of several initiatives focusing on the integration of ethnic minorities. The programme started as an experiment aimed at combating social isolation and segregation in disadvantaged communities. Seven projects commenced in 1997, and in 2001 five further projects were initiated. The projects initiated in 2001 had a time span of seven years, while the others ran for five to seven years. The 12 projects were located throughout the country, primarily in large cities. As an example, five urban regeneration projects were in progress in Copenhagen. The projects cover geographical areas with a total population of 120,000. Two-thirds of the funding granted was targeted towards urban renewal in run-down areas, and the remainder was allocated towards activities in areas such as education, employment, environment and integration of ethnic minorities.

\subsubsection{Involvement of immigrants in the local neighbourhoods}

Migrant participation in decision-making processes of urban policy and planning influences everyday life in the city, and constitutes an important element of local initiatives. Migrant participation is required to ensure stable and effective development of neighbourhoods where the resident population mainly consists of groups in need. People who are affected by urban (political) decisions should also have an influence on urban decision-making. To ensure the effective participation of households, appropriate mechanisms have to be put in place. It is important to distinguish between formal and effective participation (e.g. participation of local residents in the executive boards of (social) housing organizations, in the decision-making processes of urban renewal projects and in the redevelopment of neighbourhoods). Formal participation is not enough, participation should be much more effective in its output.

Research studies show that migrants and ethnic minorities are generally less active in democratic processes than the native population. However, it must be stressed that this is only a general picture and that differences in participation exist. The second generation of ethnic minorities is usually much more active than the first generation, 
just as there are differences between cities depending on the local traditions of political mobilisation. It is important to approach the migrant tenants at their everyday communication spots to gain access to them. The participation is positively influenced by social and economic integration in society, the size of the migrant and ethnic minority groups in the urban areas, and the availability of platforms for involvement. The basic conditions for any participation are to actively consider the migrants' demands and proposals, to make information available, and to prepare transparent structures. The information must be provided in a user friendly form in the migrants' own languages.

In a further step one should establish tenants councils and try to involve as many migrants as possible. Mere neighbourhood management is not enough - it is important to establish good neighbourhood management. Enabling participation of the local migrant population requires new forms of project management and the acquisition of new responsibilities and skills by housing providers and local authorities. The inhabitants must be given the possibility of strengthening their capacity and of participating in designing ongoing projects. Citizen participation is also a useful instrument for social change. People living in urban areas can be seen as the everyday experts in local urban affairs. The collaboration with minority social groups helps to develop governance relationships and also encourages a labour market and economic integration of these groups.

The potential for self-help of the migrants should be activated. Bottom-up perspectives, area-based initiatives and local participation contribute to "inside information" on what is going on in specific urban areas, and constitutes important feed-back on urban initiatives already being implemented.

Participation should not only be in the form of work - local public festivals with migrant participation are important events for intercultural dialogue. Urban cultural diversity and inclusion of migrants and ethnic minorities in cities add further dimensions to the importance of local citizen participation. If the objective of promoting urban cultural diversity is to be obtained, it is essential to include all groups of urban citizens in the planning and implementation of urban policy. Furthermore, participation in common policy projects with relevance to the specific urban area strengthens the contact and social interaction between different groups in the area. It increases identification with the neighbourhood and creates a sense of belonging and positive identity among the local vulnerable populations. Thus, opportunities to participate in neighbourhood decision-making processes contributes to social cohesion.

Training and providing local conflict mediators are important aspects of local conflict management. Experiences all over Europe point to the importance of promoting the establishment of alternative participation platforms and channels of influence in urban areas in order to catch up with a wide-spread lack of participation by urban citizens of foreign origin. 


\subsubsection{Substantive public investments in local infrastructure}

Investments in deprived neighbourhoods are necessary to compensate for deficits in housing stock and quality, and the lack in general infrastructure and public services. The main fields of investment are physical infrastructure improvements including apartment enlargements and renovations, formal education, community centres, schools, day care centres, youth and elderly clubs, and also financing social and community activities. Public and private investments should be better coordinated with each other. An integrated urban development policy has to involve actors external to the administration. It must be ensured that the planned investments will help to promote a well-balanced development of the urban area.

Mere housing renewal is not sufficient. Economic activity and investments on the one hand and high-quality urban structures, a sound environment and a modern and efficient infrastructure on the other hand are closely interlinked. For this reason, it is necessary to improve the design, physical condition and energy efficiency of the existing building stock in deprived neighbourhoods. High quality architecture and public spaces can strengthen people's identification with their neighbourhoods. In order to increase the sustainability of investments into the physical environment, they must be embedded in a long-term strategy which also includes private follow-up investments. The aim should be to upgrade residential areas by improving the infrastructure via integrated development of the district. Accomplishing physical infrastructure means investments in sewage, drainage, lighting etc.

A crucial requirement for improving the situation in deprived neighbourhoods is the improvement of educational and training provisions for the local community in conjunction with proactive policies aimed at children and young people. The education system in deprived neighbourhoods often suffers from many shortcomings such as a lack of financial support for schools. The answer is not simply new concepts for schools, but new forms of cooperation between schools and social work. Schools should be more strongly networked with other institutions, including ethnic community organizations. As public investments are difficult to get, schools could try to develop fund-raising ideas to get support by means of sponsorships. Companies dedicating themselves to their social responsibilities could work with educational establishments by trying to integrate projects into their corporate citizen strategy. Opportunities for education and training must be provided which are geared to the needs and the deficits of the children living in those areas to ensure equal opportunities on a longterm basis.

Measures to obtain economic stabilisation in deprived neighbourhoods must exploit economic forces inherent in the neighbourhood themselves. In this context, labour market and economic policies which are tailored to the needs of the individual neighbourhoods are appropriate instruments. The objective is to create and secure jobs and to facilitate the start-up of new businesses. Financial help and advisory activities are important to business founders, and can be provided through coaches for new micro-enterprises. 
Many deprived neighbourhoods bear the burden of poor transport connections which reduces the amenity value of these areas. In order to resolve this problem, transport planning and traffic management in these areas must increasingly aim to reduce the negative impacts of transport on the environment and to organise transport in a manner which will better integrate these neighbourhoods into the city as a whole. This will require an efficient public transport system as well as appropriate networks for pedestrian and cycle traffic.

\subsubsection{Improvement of personal security in the neighbourhood}

Security is an increasingly important feature of increasing importance in "problematic" housing estates and neighbourhoods throughout Europe. In particular in Great Britain a broad range of measures are taken to provide a security presence and to reduce crime and vandalism in troubled housing areas. Some measures are very simple and relatively cheap (there is much evidence about the positive effects of improved street lightning on reducing crime rates; women feel much safer if corridor lightning within estates is improved), whilst others are more expensive, such as fencing or walling of estates which give residents an impression that the grounds are their grounds and, likewise, provide the same impression to non-residents.

In Birmingham alone, 33 concierge schemes provide services to the tenants of 110 multi-storey blocks of flats, nearly half of the Councils flats in the city. Concierge staff is based in an office in a block of flats but provide a service to several nearby blocks (cp. Manzi \& Bowers 2003). They are linked with security staff which monitors activity around the flats and offer on-site support in an emergency outside office hours. Concierge staff is on duty from 7 a.m. to 7 p.m. every weekday. They can give general housing advice, information on repairs and lettings, and help tenants contact other council services such as Social Care and Health, the Estates Service hotline and Environmental Services. If a service is not provided by the council, concierge staff can advise tenants where they should go for information about it. Between 7 p.m. and 7 a.m., security staff is on duty. The site's security patrol makes night checks of all resident blocks and the car parks. The staff keeps an eye on communal areas with the aid of high tech surveillance cameras and electronic door entry systems. They can also contact the emergency services. Surveillance cameras are linked to a staffed 24-hour concierge centre located on-site. In addition to this, residents of some estates pay for an extra day and night security cover. Residents are also being encouraged to set up a neighbourhood watch scheme. The estate manager has regular liaison with the local police and sometimes there is an assignment with a local policy officer.

An important facet of neighbourhood security is the condition of the immediate environment and the state of repair of common areas and facilities. The "broken window syndrome" is well known all over the world. The broken window left unrepaired for some time is an invitation to break more windows. Additional money spent upon more rapid repair of public facilities which have broken down, in particular essential facilities such as lifts, and more frequent cleaning of common areas and parks appear 
to have a greater impact on residents' sense of wellbeing than money spent on expensive, high-tech security or private guard systems.

\subsubsection{Policies combining housing activities with other integration measures}

A broad and coherent political effort must include measures in addition to those in the housing sector, addressing other issues as labour market and social issues, image campaigns and the improvement of open and green spaces. Those simultaneous and composite interventions are necessary. Segregation and integration are complex problems which need complex solutions and have to be addressed at several levels at the same time. In order for such combined urban programmes to succeed, it is necessary to address the social needs of distressed neighbourhoods, hence a focus on processes as well as the products is required.

In many European cities, mixed ownership is used as an effective instrument to combat urban segregation and to promote some equality of opportunity. The ideology behind this strategy is that a mixed supply of housing and ownership makes an urban area more attractive to a mix of different groups. Consequently a mixed demand with respect to investments, trade and the local labour market is also created. By introducing an ownership element in urban areas otherwise characterised by rented social housing, deprived urban areas become increasingly attractive in terms of investment and cultural activities. Other urban instruments such as urban regeneration projects, large public cultural and sport facilities (museums, football stadiums, etc) will also be necessary.

Generally European experiences show that mixed ownership, particularly if it is combined with other urban initiatives, has a positive effect on the development of deprived areas. This is expressed by a reduction of social and ethnic segregation, the improvement of the economic situation of the area, and an increased attraction to businesses. Public-private partnerships reduce the economic risk for private partners investing in deprived urban areas. Mixed ownership housing has also a positive impact on the access of ethnic minorities to the private housing market. The price level of private housing in mixed urban areas is lower than in areas dominated by private housing. For many migrants, private housing in a mixed area constitutes an alternative to non-profit housing.

Many disadvantaged housing estates do not simply endure material difficulties, but are also burdened with poor reputations. If people only read negative press about an area, this can lead to a corresponding unfavourable image of that area. Such neighbourhoods acquire a local infamy for crime, physical neglect, unemployment or disorder. Area-based responses to the problems of such estates have tended not to address the problem of stigma directly, but have largely assumed that an estate's reputation will improve automatically as a direct result of the estate's improvement. Increasingly, regeneration initiatives have begun to recognise that overcoming the poor reputation of an estate should be a part of the regeneration process, and that this requires a growth of positive publicity for these neighbourhoods. 
However, improving the image of a deprived area is a long-lasting process. There is a lack of research which explores how the regeneration process can challenge negative images. Therefore some degree of "image management" should be a component of sustainable regeneration, as the continuation of stigma threatens the durability of investment and change, and it should be integrated with area-based approaches. Research (Hastings \& Dean, 2001) found that it is very difficult for estates to shake off a poor reputation, despite the impact of the regeneration initiative. In order to do so, it is first important to change the perceptions among stakeholders, including estate residents, residents of neighbouring areas, regeneration partners, employers, journalists and estate agents. The help of the media also seems necessary. A change in the image requires positive newspaper reporting and a proactive media relations programme to focus specifically on changing the negative perception attached to certain neighbourhoods should be implemented. Information about positive changes and key activities, cultural events, performances and achievements must be published. Establishing key spokespersons at local and regional levels will improve the efficiency of image campaigns.

A special aspect is the maintenance of outdoor spaces by residents (e.g. tenant gardens on previously unused green areas). These initiatives are promoted in many European cities. The residents benefit generally and individually by the creation of tenant gardens, and it is also proved that social contact and solidarity among residents improve. Creating tenant gardens often helps to create a good base for triggering initiative and self-organising abilities among the neighbourhood's residents. From many examples all over Europe it has become evident that the space requirements for creating tenant gardens can only be accommodated within an urban design context usually found in large-scale neighbourhoods. Already existing semi-public green spaces are very appropriate for changing into gardens for tenants.

\subsection{Policies to use opportunities provided by ethnic segregation}

Many analyses of researchers (Dangschat, 2002: 25 ff; Fassmann, 2002: 13 ff; Häussermann \& Siebel, 2001; Kulenkampff, 2005; Münch, 2007; Norris, 2007; Simpson, 2005 etc) verbalize the basic assumption that segregation cannot be avoided. It is a fact, and local authorities have no effective instruments to prevent it or to reduce it significantly. This assumption alters the policy debate. Segregation may be viewed as a condition which will continue to prevail in the future. This trend is supported by the migrants' self-interests as well as by suppression mechanisms of the housing market against groups with low income. Thus, the crucial question becomes "How can integration of immigrants in the cities be promoted despite their sociospatial segregation?” (Kulenkampff, 2005: 13; Muench, 2007).

The essence of policies which use opportunities provided by ethnic segregation is that segregated immigrant neighbourhoods have to be accepted as a permanent institution as they are necessary concomitants of immigration. Policy should not attempt to 
prevent such neighbourhoods, rather it should improve access into and out of those areas. The prime objective of such policies must be to expand the options of immigrants in the housing market by extending housing allowances, providing occupancy entitlement to housing in all areas of the city, and taking steps against discriminatory occupancy practices, such as quotas and residence restrictions. Häussermann \& Siebel (2001) say that enforced desegregation is not better than enforced segregation. According to these authors it is crucial to promote integration despite existing patterns of residential segregation. The following arguments promote a policy which accepts segregation:

- A strong argument against any anti-segregation policy is that all de-segregative measures in the past have failed to some extent.

- Ethnic segregation results from a bundle of determinants (e.g. the generally weak economic position of migrants, gentrification, suburbanization, housing market discrimination, housing preferences), which realistically cannot be controlled by the municipalities.

- One of the main sources of immigration into many EU cities is family reunion. This automatically reinforces the existing patterns of spatial segregation of the migrant population.

- In many cities social housing, where the municipality exercises allocation rights, is in short supply. This trend is further enforced because public and municipal owned housing stock has already been sold off. This makes it more difficult for local policies to influence the composition of neighbourhoods.

As the reality of segregation must be accepted, policies should be created to cope in the best possible way.

- Immigrants often lack connections in resource-strong networks with easy access to economic and social capital. Spreading them all over the city to avoid segregation exacerbates this by denying them a place of their own. The importance of local social networks, social support and social embedding of the individual migrant must be accepted by local policy.

- Effective mechanisms for informal conflict management need to be developed, and may be more effective than anti-segregative measures.

- Integration is a lengthy and conflictual process, which begins anew with every wave of immigration. Reducing segregation alone is not enough on the way to integration.

Diversity policy recognises the right of minorities and individuals to be different, therefore there is a need for differentiated urban spaces for different groups. The question is to what extent diversity policy provides concrete measures for dealing with segregation. Promoting the right to diversity together with the right to segregation is not enough to solve the problems of housing, segregation and deprived neighbourhoods.

The new policy of accepting segregation follows a line of social integration despite segregation. It enhances the integrative potential of the neighbourhood in particular in the field of ethnic economy, and hence positive results are mainly expected 
for ethnic economies. The local ethnic economy is acknowledged as a stabilising factor in the neighbourhood. Local training alliances are able to help to create apprenticeship training positions in ethnic businesses. As migrants often have to rely on informal support networks and ethnic economies, some authors (Häussermann \& Siebel, 2001) propose that it would be necessary to reduce the intensity of formal controls in the economic sector. Immigrants have difficulties in accessing formal labour markets. As a result, ethnic economies often thrive in a sort of grey area of labour legislation and overly strict application of legal regulations could dry up these resources. Economy and labour law rules therefore need to be handled more pragmatically in the case of ethnic business.

Further important policy action areas lie in education and language acquisition, participation, neighbourhood security and architecture. Policy measures should encourage tenant's participation and self-organization in promoting campaigns for increased participation of immigrants. Measures in the form of low threshold events should be implemented which enable the local migrant population to make personal contacts and directly communicate with each other, thus involving them further in local initiatives.

A basic misunderstanding with this approach is that it would promote segregation, but the acceptance of the reality of ethnic colonies must not be interpreted as a retreat from political responsibility! In many European cities the fact is that the local policy accepts the results of segregation but the politicians do not discuss the topic in public due to their perception of political correctness. Immigration requires local policymakers to perform an extraordinarily difficult balancing act to both permit and prevent segregation, to accept immigrant neighbourhoods as a lasting institution of the city, to secure public spaces, and to establish conflict management mechanisms. There cannot be a simple solution for all these problems and thus, instead of trying to alter the spatial distribution of social problems, municipalities should try to solve social problems by targeting them directly with area-based initiatives in the respective quarters instead of fighting against segregation (see Münch, 2006).

\section{Outlook}

Housing is a crucial part of the integration process for residents with migratory backgrounds. Local housing policies have to deal with the specific housing situation of migrants, often within the scope of general housing policies for vulnerable groups. The supply and provision of access to affordable social housing seems to be a major method of ensuring decent housing for low income groups of migrants. The spatial concentration of social housing units is also an important aspect. The spread of social housing and small units of social housing across the city are highly relevant for the integration process of migrants allocated in social housing. However cities are also aware that some degree of concentration cannot be avoided. 